\title{
Prevalence of Waterpipe Smoking among Rural Pregnant Women in Southern Iran
}

\author{
Alireza Mirahmadizadeh $^{\mathrm{a}}$ Nouzar Nakhaee ${ }^{\mathrm{b}}$

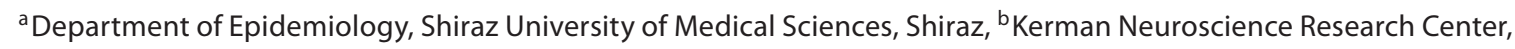 \\ Kerman University of Medical Sciences, Kerman, Iran
}

\section{Key Words}

Pregnancy $\cdot$ Waterpipe $\cdot$ Low birth weight $\cdot$ Risk factor $\cdot$ Iran

\begin{abstract}
Objective: To estimate the prevalence of waterpipe smoking among rural pregnant women in Southern Iran and to identify the impact of maternal waterpipe smoking on baby's birth weight. Subjects and Methods: A population-based survey was conducted in rural areas of Southern Iran in 2004 using existing health records and interviewing all mothers during the 10 days after delivery. Maternal exclusion criteria included cigarette smoking during pregnancy, a history or occurrence of epilepsy, diabetes and hypertension (gestational and/or essential) during pregnancy, factors that have been proved to have detrimental effects on birth weight. Results: Of the 2,808 mothers interviewed, 224 (8\%) were waterpipe smokers of which 90 (3.2\%) and 134 (4.8\%) were occasional (smoking less than once per day) and daily (at least once per day) smokers, respectively. Six hundred and seventy-four (24\%) were passively exposed to waterpipe smoke during pregnancy and 322 (11.5\%) were exposed to second-hand cigarette smoke. Mothers who started smoking during the first trimester had lower birth weight babies $(3,215 \pm 612 \mathrm{~g})$ compared to those who started smoking during the second or third trimesters $(3,447 \pm 550 \mathrm{~g}$, $p=0.04)$. Conclusion: Waterpipe smoking during pregnancy is prevalent in Southern Iran and appears to be a risk factor for low birth weight babies.

Copyright @ 2008 S. Karger AG, Basel
\end{abstract}

(C) 2008 S. Karger AG, Basel

$1011-7571 / 08 / 0176-0435 \$ 24.50 / 0$

Fax +4161306 1234

E-Mail karger@karger.ch

www.karger.com
Accessible online at:

www.karger.com/mpp

\section{Introduction}

Waterpipe smoking is known by various names in different regions: Narghile in Turkey and Syria, Shisha in Egypt and Kuwait, Hookah in India and Qalyan in Iran [1]. The tobacco used in waterpipe smoking is of three types: 'Mu'essel' (30\% tobacco and 70\% honey or molasses); the traditional 'ajami' (Persian unflavored) pure dark paste tobacco, and 'Jurak', which is an intermediate form used generally in India [2]. In Iran most rural women who smoke waterpipe use the traditional unflavored tobacco, in contrast to neighboring regions in which the flavored tobacco (Mu'essel) is more popular [3]. Waterpipe smoking is oriental in origin [4], but its use is spreading worldwide possibly due to immigration [2].

Despite popular belief, waterpipe smokers are at risk for the same kind of diseases as cigarette smokers that include cancer and ischemic heart disease [1]. Although the smoke from waterpipe passes through water before inhalation, a waterpipe smoker may inhale as much smoke in a 1-hour smoking session as a cigarette smoker would inhale consuming 100 or more cigarettes [1]. Limited research has been done on the adverse effects of waterpipe smoking [3,5-8], and based on a Medline search from 1966 to early 2008 only three reports $[5,7,8]$ have been published on its effects on pregnancy outcomes.

In regard to cigarette smoking, a causal relationship exists between waterpipe smoking in pregnancy and adverse birth outcomes [9]. Mothers who smoke during 
pregnancy generally deliver infants weighing from 100 to $300 \mathrm{~g}$ less than those born to nonsmoking mothers [9, 10].

The high prevalence of waterpipe smoking (15-20\%) among rural women residing in Southern Iran [11] and the quality of maternal and child health programs in rural health centers in Iran [12] provide an almost unique opportunity to investigate the adverse effects of waterpipe smoking during pregnancy. The aim of this study was to estimate the prevalence of waterpipe smoking among rural pregnant women in Southern Iran and its impact on neonatal birth weight.

\section{Subjects and Methods}

This cross-sectional community-based study was conducted in rural areas of Booshehr Province, South Iran, known for its high prevalence of waterpipe smoking. Approximately 430,000 inhabitants live in about 1,000 villages and have access to health services provided by caregivers (behvarzes) in health houses. The behvarzes who receive 2 years of training live in the same village where they work. The female behvarz is in charge of maternal and child health care and all services are provided free of charge [12]. All health houses in the rural health centers were included in the study and all births that occurred in the rural areas during the 2004 calendar year were studied.

The World Health Organization (WHO) recommendation [13] was used to classify the pregnant women into nonsmokers, occasional and daily waterpipe smokers. A nonsmoker was a pregnant woman who did not smoke during pregnancy; an occasional smoker did not smoke every day, and a daily smoker smoked at least once every day. They were asked to indicate the trimester in which they started waterpipe smoking. Passive smoking was assessed by whether or not they frequently inhaled waterpipe or cigarette smoke at or outside the home during the recent pregnancy. Low birth weight was defined as a neonatal birth weight less than 2,500 g according to WHO [14] definition. Maternal exclusion criteria were cigarette smoking during pregnancy, a history or occurrence of epilepsy, diabetes and hypertension (gestational and/or essential) during pregnancy, multiple pregnancy and factors that have been proven to have detrimental effects on birth weight [14]. Obstetric history and birth weights were obtained from health records that were kept in health houses. To minimize recall bias, all mothers were interviewed during the 10 days after delivery regarding waterpipe and cigarette smoking status during pregnancy after obtaining their consent. They were interviewed either in health houses or at home. To cross-check the validity of the data gathering process, supervisors interviewed some women at home.

The $t$ test and ANOVA were used to compare group means; $\chi^{2}$ for trend test was used for analyzing qualitative data. Using multivariate logistic regression the association between low birth weight and waterpipe smoking was analyzed while controlling for the potential confounders. Statistical analyses were conducted using the SPSS 13.0 statistical package (SPSS, Inc., Chicago, Ill., USA).

\section{Results}

Of the 2,882 women, 74 were excluded from analysis due to incomplete data; hence 2,808 were analyzed. The baseline characteristics of the study sample according to waterpipe smoking status are shown in table 1 . Of the 2,808 pregnant women, $224(8 \%)$ were waterpipe smokers: 90 (3.2\%) and $134(4.8 \%)$ were occasional and daily smokers, respectively. Of the 224 waterpipe smokers, 220 (99.2\%) used unflavored tobacco.

Three hundred and twenty-two (11\%) women were exposed to cigarette smoke passively and $674(24 \%)$ were passively exposed to waterpipe smoke during pregnancy (table 1). Passive exposure to waterpipe smoking was more prevalent than cigarette smoking and the difference was statistically significant $(\mathrm{p}=0.001)$.

The prevalence of low birth weight delivery was 8.2, 4.4 and $5.8 \%$ in daily smokers, occasional smokers and nonsmokers, respectively $(\mathrm{p}=0.34)$ as summarized in table 1 . Birth weight was lower in mothers $(n=189)$ who smoked throughout pregnancy $(3,215 \pm 612 \mathrm{~g})$ compared to those $(n=35)$ who started smoking during the second or third trimester $(3,447 \pm 550 \mathrm{~g}, \mathrm{p}=0.04)$.

The multiple logistic regression analyses in table 2 show that being a daily waterpipe smoker raised the odds of low birth weight by $37 \%$ (OR 1.37, 95\% CI 0.72-2.60). The highest odds ratio of low birth weight was associated with the existence of any important disease during pregnancy (OR 2.06, 95\% CI 1.31-3.23). Women with a higher number of prenatal visits were less likely to deliver a low birth weight neonate (OR 0.94, 95\% CI 0.92-0.97).

\section{Discussion}

Smoke from the waterpipe has been proven to be as harmful to health as that of cigarettes, and waterpipe smokers inhale a significant amount of the same noxious substances found in cigarettes [15]. The results of two recent studies have shown that some heavy metals such as arsenic, chromium, and lead and also tar have higher levels in a single waterpipe smoking session compared to the smoke of a single cigarette $[15,16]$. Considering the incremental trend of waterpipe consumption in the Eastern Mediterranean Region and throughout the world [17] and positive attitude of women to waterpipe smoking [2, 11], more concern should be devoted to research in this field especially on women.

The $8 \%$ prevalence of waterpipe smoking in the region among pregnant women was higher than that reported 
Table 1. Selected sociodemographic and pregnancy-related characteristics according to waterpipe smoking status among 2,808 rural women residing in Southern Iran

\begin{tabular}{|c|c|c|c|c|c|}
\hline Characteristic & $\begin{array}{l}\text { Daily } \\
\text { smokers }\end{array}$ & $\begin{array}{l}\text { Occasional } \\
\text { smokers }\end{array}$ & Nonsmokers & Total sample & $\mathrm{p}$ \\
\hline \multicolumn{6}{|c|}{ Passive exposure to cigarette smoke } \\
\hline Yes & $23(17.2)$ & $16(17.8)$ & $283(11.0)$ & $322(11.5)$ & \multirow[t]{2}{*}{0.014} \\
\hline No & $111(82.8)$ & $74(82.2)$ & $2,301(89.0)$ & $2,486(88.5)$ & \\
\hline \multicolumn{6}{|c|}{ Passive exposure to waterpipe smoke } \\
\hline Yes & $121(90.3)$ & $73(81.1)$ & $480(18.6)$ & $674(24.0)$ & \multirow[t]{2}{*}{0.001} \\
\hline No & $13(9.7)$ & $17(18.9)$ & $2,104(81.4)$ & $2,134(76.0)$ & \\
\hline \multicolumn{6}{|c|}{ History of any severe disease during pregnancy } \\
\hline Yes & $17(12.7)$ & $9(10.0)$ & $230(8.9)$ & $256(9.1)$ & \multirow[t]{2}{*}{0.32} \\
\hline No & $117(87.3)$ & $81(90.0)$ & $2,354(91.1)$ & $2,552(90.9)$ & \\
\hline \multicolumn{6}{|l|}{ Parity } \\
\hline Primiparous & $21(15.7)$ & $10(11.1)$ & $730(28.3)$ & $761(27.1)$ & \multirow[t]{2}{*}{0.001} \\
\hline Multiparous & $113(84.3)$ & $80(88.9)$ & $1,854(71.7)$ & $2,042(72.9)$ & \\
\hline \multicolumn{6}{|l|}{ Type of delivery } \\
\hline Normal vaginal & $105(78.4)$ & $73(81.1)$ & $1,929(74.7)$ & $2,107(75.0)$ & \multirow[t]{3}{*}{0.001} \\
\hline Cesarean & $29(21.6)$ & $15(16.7)$ & $650(25.2)$ & $694(24.7)$ & \\
\hline Instrumental & $0(0)$ & $2(2.2)$ & $5(0.2)$ & $7(0.3)$ & \\
\hline \multicolumn{6}{|l|}{ Duration of gestation } \\
\hline$<37$ weeks & $6(4.5)$ & $2(2.2)$ & $76(2.9)$ & $84(3.0)$ & \multirow[t]{2}{*}{0.54} \\
\hline$\geq 37$ weeks & $128(95.5)$ & $88(97.8)$ & $2,508(97.1)$ & $2,724(97.0)$ & \\
\hline \multicolumn{6}{|l|}{ Birth weight } \\
\hline$<2,500 \mathrm{~g}$ & $11(8.2)$ & $4(4.4)$ & $150(5.8)$ & $165(5.9)$ & \multirow[t]{2}{*}{0.43} \\
\hline$\geq 2,500 \mathrm{~g}$ & $123(91.8)$ & $86(95.6)$ & $2,434(94.2)$ & $2,643(94.1)$ & \\
\hline Birth weight, $g$ & $3,217.5 \pm 619.5$ & $3,324.4 \pm 570.7$ & $3,246.1 \pm 538.1$ & $3,247.3 \pm 543.4$ & 0.33 \\
\hline
\end{tabular}

Number of subjects with percentage in parentheses, mean \pm SD for birth weight.

by Bachir and Chaaya [7] (6.1\%) and Tamim et al. [8] (5.1\%) on Lebanese pregnant women. A comparison of the two national health surveys conducted in 1991 and 1999 revealed an increase in the prevalence of waterpipe smoking (from 0.8 to $1.4 \%$ ) among Iranian adolescents [18]. Considering the prevalence of cigarette smoking in Iranian women, which is $1.2 \%$ in rural [19] and 3.6\% in urban areas [20], the prevalence of waterpipe smoking seems to be roughly 7 times higher than that of cigarette smoking, indicating a preference of Iranian women for waterpipe smoking, thereby confirming societal acceptance of women smoking waterpipe [21]. It is noteworthy that the exclusion of cigarette smokers is likely to underestimate the prevalence of waterpipe use since some of them smoke both cigarettes and waterpipe.

The prevalence of low birth weight in the total sample was $5.9 \%$ (95\% CI 5.5-6.3), which is comparable to the national level [22]. Prevalence of low birth weight was higher in daily smokers (8.2\%) than in nonsmokers (5.8\%), but the difference was not statistically significant, raising
Table 2. Predictors of low birth weight among 2,808 rural women residing in Southern $\operatorname{Iran}^{1}$

\begin{tabular}{llll}
\hline Variable & $\begin{array}{l}\text { Adjusted } \\
\text { OR }\end{array}$ & & \\
& & & \\
\hline Waterpipe smoking & 1 & & \\
$\quad$ No & 0.75 & $0.27-2.07$ & 0.57 \\
$\quad$ Occasional & 1.37 & $0.72-2.60$ & 0.34 \\
$\quad$ Daily & 1 & & \\
Passive exposure to cigarette smoke & & \\
$\quad$ No & 1.42 & $0.92-2.21$ & 0.11 \\
$\quad$ Yes & 1 & & \\
Any important disease during pregnancy & & \\
$\quad$ No & 2.06 & $1.31-3.23$ & 0.002 \\
$\quad$ Yes & 0.99 & $0.98-1.01$ & 0.37 \\
Maternal weight before pregnancy & 0.96 & $0.94-0.99$ & 0.009 \\
Maternal height & 0.94 & $0.92-0.97$ & 0.001 \\
Number of prenatal visits & & & \\
\end{tabular}

${ }^{1}$ Only variables with a univariable $\mathrm{p} \leq 0.25$ were considered for inclusion in the multiple logistic regression model.

$\mathrm{OR}=$ Odds ratio $; 95 \% \mathrm{CI}=95 \%$ confidence interval. 
the question of a sufficiently powered study. Post hoc power analysis showed that we had not the optimal power to detect the observed difference (22\%). Overall, the proportion of low birth weight infants born to waterpipe smoker mothers was $6.7 \%$, which is similar to the $7.5 \%$ reported by Nuwayhid et al. [5]. They also found a decrease in birth weight of babies born to mothers who smoked more than once a day, but the difference was not statistically significant and the authors presumed that it was due to small sample size [5].

Time of onset of waterpipe smoking had a negative impact on birth weight as $84 \%$ who smoked waterpipe from the first trimester of pregnancy had lower mean birth weight babies than those who started smoking later $(\mathrm{p}<0.05)$, and this finding is similar to findings reported by others [7]. Similar findings have been reported [23] for cigarette smoking. It could be inferred that the hazardous effects of waterpipe smoking might be more prominent in the first trimester, which may be due to its harmful effects on the developing embryo or fetus [5] or longer exposure to the fetus.

To overcome the confounding effects of other independent variables, multivariate analysis was done, and the most potent predictor for low birth weight was a severe disease during pregnancy, although waterpipe smoking showed some risk (OR of daily smoking $=1.37)$ but was not significant statistically (table 2). Other studies [5, $7,8]$ had higher OR for predicting low birth weight due to waterpipe and cigarette smoking. Therefore adequate comparison cannot be made between our study and those of others $[5,7,8]$. The number of prenatal visits showed a beneficial effect as reported previously concerning cigarette smoking and may be indirectly related to socioeconomic status [24] of the study group.

This study has several limitations that include limited research on adverse effects of waterpipe smoking to which appropriate comparison could be made; social inequality as a confounding risk factor was not included in the multivariate logistic analysis; recall bias could not be ruled out because this was a retrospective study, and a larger sample size is needed to draw a definitive inference on the association between maternal pipe smoking and neonatal low birth weight.

\section{Conclusion}

Waterpipe smoking during pregnancy is prevalent in Southern Iran and may be a risk factor for neonatal low birth weight because of high concentration of chemical compounds in waterpipe smoke that could have toxic effects.

\section{Acknowledgments}

This research was funded by the Eastern Mediterranean Regional Office (EMRO) of the World Health Organization (WHO). The authors thank reviewers for helpful comments.

\section{References}

1 World Health Organization (Tobacco Free Initiative): Advisory Note. Waterpipe Tobacco Smoking: Health Effects, Research Needs and Recommended Actions by Regulators 2005. http://www.who.int/tobacco/global_ interaction/tobreg/en/ (retrieved 1 July 2005).

2 Knishkowy B, Amitai Y: Water-pipe (narghile) smoking: an emerging health risk behavior. Pediatrics 2005;116:e113-e119.

3 Radwan GN, Mohamed MK, El-Setouhy M, Israel E: Review on waterpipe smoking. J Egypt Soc Parasitol 2003;33(3 suppl):10511071.

4 Chaouachi K: A critique of the WHO TobReg's 'Advisory Note' report entitled: 'Waterpipe tobacco smoking: health effects, research needs and recommended actions by regulators'. J Negat Results Biomed 2006;5: 17.
5 Nuwayhid IA, Yamout B, Azar G, Kambris MA: Narghile (hubble-bubble) smoking, low birth weight, and other pregnancy outcomes. Am J Epidemiol 1998;148:375-383.

6 Maziak W, Ward KD, Afifi Soweid RA, Eissenberg $\mathrm{T}$ : Standardizing questionnaire items for the assessment of waterpipe tobacco use in epidemiological studies. Public Health 2005;119:400-404.

7 Bachir R, Chaaya M: Maternal smoking: determinants and associated morbidity in two areas in Lebanon. Matern Child Health J 2008;12:298-307.

8 Tamim H, Yunis KA, Chemaitelly H, Alameh M, Nassar AH: Effect of narghile and cigarette smoking on newborn birthweight. BJOG 2008;115:91-97.

9 Kirchengast S, Hartmann B: Nicotine consumption before and during pregnancy affects not only newborn size but also birth modus. J Biosoc Sci 2003;35:175-188.
10 Kallen K: The impact of maternal smoking during pregnancy on delivery outcome. Eur J Public Health 2001;11:329-333.

11 Majdzadeh SR, Zamani G, Kazemi SH: Barresie keifie avamele geraayeshe mardome hormozgan be estemaale Qalyan va raah haaye monasebe mobareze ba an (Qualitative survey on the factors affecting tendency to hookah in Hormozgan province and appropriate campaign methods against it). Hakim 2001;5:183-187.

12 Shadpour K: Primary health care networks in the Islamic Republic of Iran. East Mediterr Health J 2000;6:822-825.

13 World Health Organization: Guidelines for Controlling and Monitoring the Tobacco Epidemic. Geneva, WHO, 1998.

14 Kramer MS: Determinants of low birth weight: methodological assessment and meta-analysis. Bull World Health Organ 1987;65:663-737. 
15 Shihadeh A: Investigation of mainstream smoke aerosol of the arghileh waterpipe. Food Chem Toxicol 2003;41:134-152.

16 Shihadeh A, Saleh R: Polycyclic aromatic hydrocarbons, carbon monoxide, 'tar', and nicotine in the mainstream smoke aerosol of the narghile waterpipe. Food Chem Toxicol 2005;43:655-661.

17 Maziak W, Ward KD, Afifi Soweid RA, Eissenberg T: Tobacco smoking using a waterpipe: a re-emerging strain in a global epidemic. Tob Control 2004;13:327-333.

18 Mohammad K, Noorbala AA, Madjdzadeh R, Karimloo M: Ravande taghirate shoyoe estemale dokhaniat dar iran (1370-1378) bar asase do tarhe mellie salamat va bimari (Trend of smoking prevalence in Iran from 1991 to 1999 based on two National Health Surveys). Hakim 2000;4:290-297.
19 Golshan M, Estekib, Dadvand P: Prevalence of chronic bronchitis and chronic respiratory symptoms in adults over the age of 35 years in Isfahan, Iran in 1998. Respirology 2001;6:231-235.

20 Ahmadi J, Khalili H, Jooybar R, Namazi N, Mohammadagaei P: Prevalence of cigarette smoking in Iran. Psychol Rep 2001;89:339341.

21 Asfar T, Ward KD, Eissenberg T, Maziak W: Comparison of patterns of use, beliefs, and attitudes related to waterpipe between beginning and established smokers. BMC Public Health 2005;5:19.
22 Wardlaw T, Blanc A, Zupan J, Ahman E: Low Birth Weight Country, Regional and Global Estimates. Geneva, The United Nations Children's Fund and World Health Organization, 2004.

23 Bernstein IM, Mongeon JA, Badger GJ, Solomon L, Heli SH, Higgins ST: Maternal smoking and its association with birth weight. Obstet Gynecol 2005;106:986-991.

24 Desjardins E, Hardwick D: How many visits by health professionals are needed to make a difference in low birth weight? A dose-response study of the Toronto Healthiest Babies Possible Program. Can J Public Health 1999;90:224-228. 